CONGENITAL HEART DISEASE

\title{
Percutaneous closure of patent foramen ovale: impact of device design on safety and efficacy
}

\author{
M Schwerzmann, S Windecker, A Wahl, H Mehta, K Nedeltchev, H Mattle, C Seiler, B Meier
}

Heart 2004;90:186-190. doi: 10.1136/hrt.2002.003111

See end of article for authors' affiliations

.....................

Correspondence to: Dr Bernhard Meier, Swiss Cardiovascular Centre Bern, University Hospital Inselspital, 3010 Bern, Switzerland; bernhard meier@insel.ch

Accepted 9 June 2003
Objective: To compare the safety and efficacy of percutaneous closure of patent foramen ovale (PFO) with the Amplatzer PFO occluder (Amplatzer) or the PFO STAR device (STAR) in patients with presumed paradoxical embolism.

Methods: Implantation characteristics, procedural complications, residual shunt, and recurrence of thromboembolic events were recorded prospectively in 100 consecutive patients undergoing percutaneous PFO closure with the STAR $(n=50)$ or Amplatzer $(n=50)$ devices between 1998 and 2001 . The study was not randomised. Device implantation was successful in all cases.

Results: There were more procedural complications in the STAR than in the Amplatzer group (8/50 v 1/50, $p=0.01$ ). More than one device placement attempt was an independent predictor of procedural complications (odds ratio (OR) 8.5, 95\% confidence interval $(\mathrm{Cl}) 1.3$ to $55.8 ; \mathrm{p}=0.03$ ). A residual shunt six months after PFO closure, assessed by transoesophageal contrast echocardiography, occurred more often in the STAR than the Amplatzer group (17/50 v 3/50, $p=0.004)$, and was predicted in the STAR group by the use of a device with a $5 \mathrm{~mm}$ as opposed to a $3 \mathrm{~mm}$ disc connector (OR 6.1, 95\% Cl 1.1 to 34.0; $\mathrm{p}=0.04)$. The actuarial risk of recurrent thromboembolic events after 3.5 years was $16.8 \% 195 \% \mathrm{Cl} 7.6 \%$ to $34.6 \%)$ in the STAR and $2.7 \%(95 \% \mathrm{Cl} 0.4 \%$ to $17.7 \%)$ in the Amplatzer group after three years ( $\mathrm{p}=0.08$ ).

Conclusions: Percutaneous PFO closure with the Amplatzer PFO occluder had fewer procedural complications and was more likely to be complete than with the STAR device. These findings underline the importance of device design for successful percutaneous PFO closure.
A patent foramen ovale (PFO) has been related to such disease manifestations as paradoxical embolism, ${ }^{1}$ orthostatic desaturation in the setting of the platypnoea-orthodeoxia syndrome, ${ }^{2}$ refractory hypoxaemia in patients with right ventricular infarction ${ }^{3}$ or pulmonary hypertension, ${ }^{5}$ decompression illness and ischaemic cerebral lesions in divers, ${ }^{67}$ and migraine with aura. ${ }^{89}$ The association of PFO and cryptogenic stroke in young adults has been confirmed in a recent meta-analysis. ${ }^{10}$ Larger PFO size, ${ }^{11}$ a greater right to left shunt, ${ }^{12}$ and the presence of an atrial septal aneurysm (ASA) $)^{13}$ appear to increase the risk of paradoxical embolism. Percutaneous PFO closure has been shown to be feasible in patients with presumed paradoxical embolism. ${ }^{14-16}$ Its therapeutic value in comparison with medical treatment is currently under investigation. ${ }^{17}$

Previous studies of percutaneous PFO closure employed a variety of transseptal occlusion devices primarily designed for the closure of atrial septal defects. ${ }^{14-17}$ An appreciation of the functional and structural differences between PFO and atrial septal defect led to the recent development of two dedicated PFO occlusion devices, the Amplatzer PFO occluder (Amplatzer) (AGA Medical, Golden Valley, Minnesota, USA) ${ }^{18}$ and the PFO STAR device (STAR) (Cardia, Burnsville, Minnesota, USA) (figs 1 and 2). The two devices differ in design, material, deployment sheath, disc size, connector length and flexibility, septal fixation, and retrievability. Manufacturing properties may have an impact on the implantation procedure, long term outcome, and clinical condition of the patient.

Our aim in the present study was to compare these two devices in patients with presumed paradoxical embolism undergoing percutaneous $\mathrm{PFO}$ closure with respect to procedural complications, completeness of PFO closure, and the clinical recurrence of paradoxical embolism.

\section{METHODS}

\section{Patient population}

One hundred consecutive patients undergoing percutaneous PFO closure between July 1998 and March 2001 with a STAR or an Amplatzer devices were included in the study. All patients had suffered from ischaemic stroke or symptoms of a transient ischaemic attack (TIA) with neuroradiological confirmation of cerebral ischaemia, and the mechanism of ischaemia was presumed to be paradoxical embolism. All patients underwent multiplane transoesophageal contrast echocardiography, carotid Duplex scanning, and 24 hour Holter ECG recording before their inclusion in the study. The clinical diagnosis of paradoxical embolism was based on the absence of a left sided thromboembolic source and a PFO mediated right to left shunt. The presence of a PFO with the potential for right to left shunt was confirmed during multiplane transoesophageal contrast and colour Doppler echocardiography. Aerated colloid solution was injected into an antecubital vein, followed by flushing with $10 \mathrm{ml}$ normal saline to opacify the right atrium. All patients were coached to perform a Valsalva manoeuvre just before the injection, with release after arrival of contrast medium in the right atrium. Bulging of the septum into the left atrium had to be present. The injections were done in two orthogonal echocardiographic planes. The maximum number of contrast injections was four, two in every plane. The PFO mediated right to left shunt was graded according to the quantity of bubbles crossing the septum within four cardiac cycles after full opacification of the right atrium: minimal if only a few bubbles passed, moderate if a cloud of bubbles passed, and

Abbreviations: ASA, atrial septal aneurysm; PFO, patent foramen ovale; TIA, transient ischaemic attack 


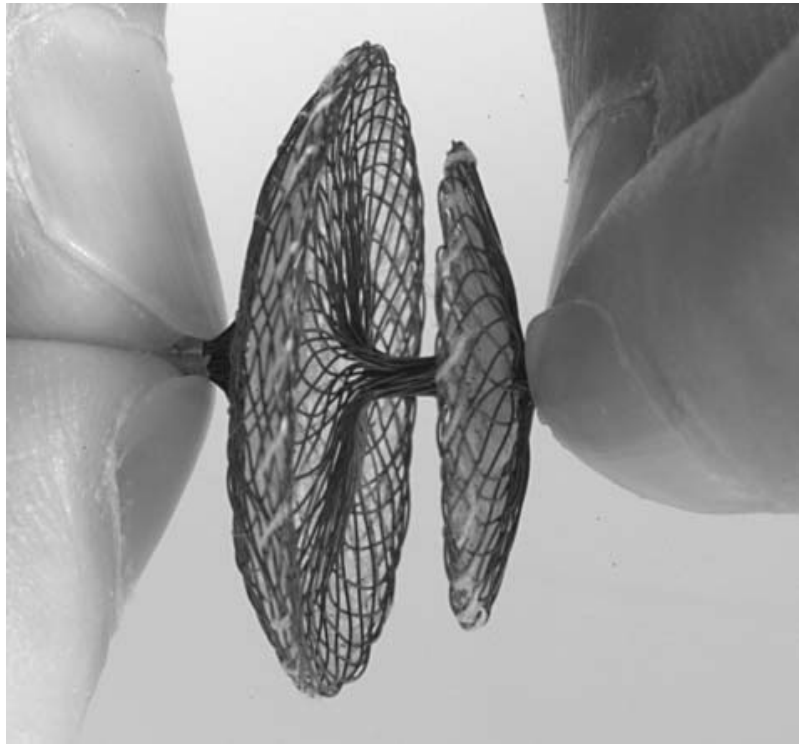

Figure 1 Amplatzer PFO occluder with larger right atrial than left atrial disc consisting of a nitinol wire mesh. The discs are filled with thin polyester fabric.

severe if there was intense opacification of the left atrium. ${ }^{11} \mathrm{~A}$ colour Doppler and duplex examination of the extracranial carotid and vertebral arteries, a 12 lead ECG, and a Holter ECG were done routinely.

The study was approved by the local ethics committee, and all patients were asked to give their informed consent.

\section{Device implantation}

The technique of percutaneous PFO closure has been described in detail. ${ }^{16}$ Venous access was gained through the right femoral vein under local anaesthesia. Device implantation was guided by fluoroscopy and right atrial angiography. Transoesophageal echocardiography was not used during the procedure.

Each device was implanted in 50 patients at the discretion of a single operator. No formal algorithm for randomisation was used. The size of device was chosen depending on body size and weight, left atrial size, atrial septal anatomy (that is, the presence of an atrial septal aneurysm), and the distance of defect to the mitral valve and aortic sinus. Transthoracic echocardiography was done the day after device implantation to confirm correct device position before discharge. All patients were treated with $100 \mathrm{mg}$ aspirin daily until transoesophageal echocardiography revealed no or only minimal residual shunting at six months.

\section{Follow up}

Patients were followed prospectively for a mean of 2.0 years (range 0.5-3.7 years), using a structured telephone interview, addressing recurrence of embolism (TIA, stroke, or peripheral embolism), and device related complications (device embolisation, disc thrombi, arrhythmias, or vascular complications at the access site). Any reported symptoms compatible with an embolic event were considered a primary end point, even in the absence of imaging studies. Multiplane transoesophageal contrast echocardiography was repeated six months after percutaneous PFO closure to assess the device and completeness of PFO closure. A residual right to left shunt was graded according to the quantity of bubbles crossing the septum within four cardiac cycles, applying the criteria of the baseline examination. ${ }^{11}$

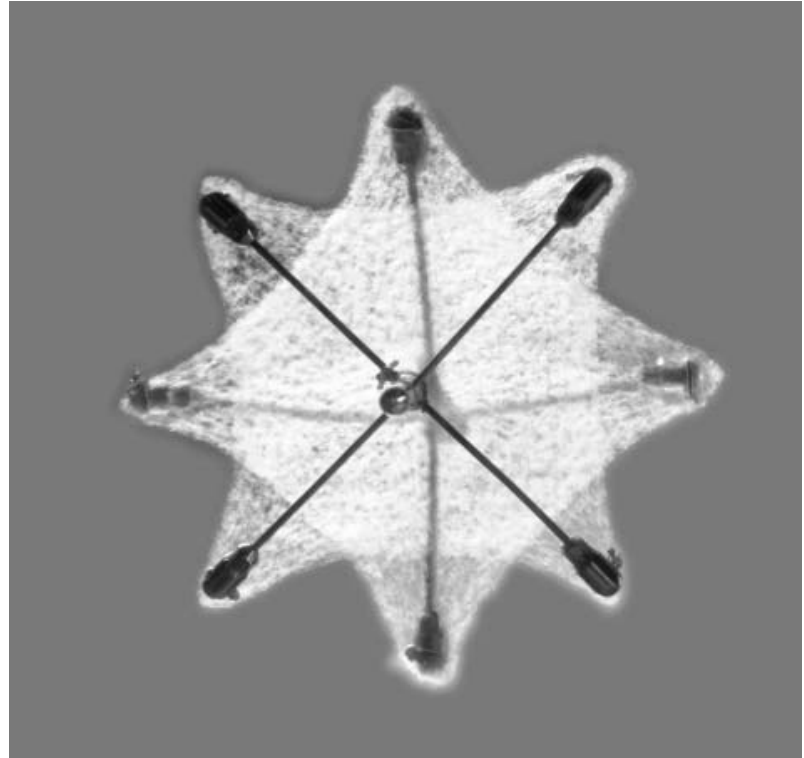

Figure 2 PFO STAR device consisting of two ivalone squares spread by crossing blunted nitinol wires.

\section{Statistical analysis}

Groups were compared using a two sided unpaired $t$ test for continuous data, and $\chi^{2}$ analysis for nominal data. Actuarial freedom from recurrent embolic events was calculated using the Kaplan-Meier method. Potential risk factors for procedural complications and a residual shunt were identified by logistic regression analysis. A Cox proportional hazards model calculated the odds ratios for predictors of recurrent embolic events. Owing to the limited number of outcome events, a multivariate adjustment was not done..$^{19}$ Data are expressed as mean (SD) and as odds ratios (OR) with 95\% confidence intervals (CI). Statistical significance was assumed at a probability value of $\mathrm{p}<0.05$. All data were analysed using STATA 5.0 statistical software (Stata Corporation, College Station, Texas, USA).

\section{RESULTS}

\section{Patient characteristics}

Baseline clinical characteristics were well matched in both patient groups with respect to age, sex, cardiovascular risk factors, and thromboembolic index events (table 1). Transoesophageal contrast echocardiography showed no differences in atrial septal anatomy, degree of right to left shunting, or presence of an atrial septal aneurysm between the two groups (table 2).

\section{Procedural outcome}

Percutaneous PFO closure was successful in all patients. However, more placement attempts were required with the STAR than with the Amplatzer device for successful PFO closure (table 3). Procedure and fluoroscopy times were longer for the STAR than for the Amplatzer group (table 3). Procedural complications were more common with the STAR device than with the Amplatzer device (8/50 v 1/50; $p=0.01)$. In one patient, the STAR device embolised into the pulmonary artery immediately after release, requiring removal with a retrieval basket and correct repositioning in the PFO. In another patient, the STAR device embolised into the descending aorta during follow up, although transthoracic echocardiography had confirmed adequate device position 12 hours after implantation. The device was retrieved 
Table 1 Baseline characteristics

\begin{tabular}{lccc}
\hline & $\begin{array}{c}\text { PFO STAR } \\
(\mathbf{n}=50)\end{array}$ & $\begin{array}{l}\text { Amplatzer PFO occluder } \\
(\mathbf{n}=50)\end{array}$ & p Value \\
\hline Age (years) & $50(14)$ & $50(12)$ & NS \\
Male sex (\%) & 50 & 42 & NS \\
Body mass index (kg/m $\left.{ }^{2}\right)$ & $26(5)$ & $25(4)$ & 0.02 \\
Follow up (years) & $2.2(0.8)$ & $1.9(0.6)$ & NS \\
Cardiovascular risk factors & 26 & 26 & NS \\
Hypertension (\%) & 2 & 6 & NS \\
Diabetes mellitus (\%) & 32 & 26 & NS \\
Smoking (\%) & 24 & 12 & NS \\
Family history of CAD (\%) & 44 & 48 & NS \\
Dyslipidaemia (\%) & 34 & 36 & NS \\
Embolic index event & 64 & 62 & NS \\
TIA (\%) & 2 & 2 & NS \\
Stroke (\%) & 44 & 38 & \\
Diving accident (\%) & $1.9(1.1)$ & $1.8(1.1)$ & \\
$>1$ event (\%) & & & \\
Mean number of events & & &
\end{tabular}

percutaneously, and the PFO was subsequently closed with an Amplatzer device.

Regression analysis showed two independent predictors of procedural complications: the type of device used (OR for STAR $8.8,95 \%$ CI 1.1 to $74.4 ; \mathrm{p}=0.04$ ); and more than one placement attempt to position the device correctly (OR for more than one attempt $8.5,95 \%$ CI 1.3 to $55.8 ; \mathrm{p}=0.03$ ) (table 4).

\section{Echocardiographic outcome}

Six months after device implantation, transoesophageal contrast echocardiography showed more complete PFO occlusion with the Amplatzer than with the STAR device (table 2). Thus complete PFO closure was achieved in 47 patients (94\%) with the Amplatzer device versus 33 (66\%) with the STAR device $(p<0.001)$. A severe shunt persisted in eight patients $(16 \%)$ with a STAR device but in none with an Amplatzer device ( $p=0.002)$. In a univariate logistic regression analysis, the use of a STAR device (OR 8.4, 95\% CI 1.8 to $40.1 ; \mathrm{p}=0.01$ ), the presence of a long disc connector ( $5 \mathrm{~mm}$ instead of $3 \mathrm{~mm}$ ) in the case of the STAR device (OR $6.1,95 \%$ CI 1.1 to $34.0 ; \mathrm{p}=0.04)$, and probably the implantation of a device larger than $30 \mathrm{~mm}$ in diameter independent of the device type (OR 2.9, 95\% CI 0.9 to 9.7; $\mathrm{p}=0.06$ ) correlated with a significant residual shunt six months after device implantation (table 4).

\section{Clinical outcome}

The mean (SD) follow up period was 2.0 (0.7) years for at total of 201 patient-years and was somewhat longer for the STAR group owing to the earlier availability of the STAR device (table 1). There was one death from a non-related motor vehicle accident. During follow up, seven recurrent neurological events were observed: three minor strokes without permanent neurological sequelae and four TIAs. The first event, a minor stroke, occurred three months, and the latest event 26 months, after device implantation. Two of the seven recurrent neurological events occurred with concomitant antiplatelet treatment, while five events were observed in patients on no active drug treatment. Transoesophageal contrast echocardiography showed a residual shunt in only one of seven patients with a recurrence. In all but one of the patients with a recurrence, at least one cardiovascular risk factor was present. The actuarial recurrence rate after 3.5 years for TIA or stroke was $10.6 \%$ (4.9\% to $22.3 \%$ ) for all patients, with a trend for more freedom from recurrence with the Amplatzer device (fig 3).

\section{DISCUSSION}

The therapeutic efficacy of percutaneous PFO closure in the prevention of recurrent thromboembolic events has been comparable with medical treatment and surgical PFO closure in observational studies. ${ }^{13-17} 20-22$ In the absence of data from

Table 2 Echocardiographic findings

\begin{tabular}{llll}
\hline & $\begin{array}{l}\text { PFO STAR } \\
(\mathbf{n}=50)\end{array}$ & $\begin{array}{l}\text { Amplatzer PFO } \\
\text { occluder ( } \mathbf{n}=50)\end{array}$ & p Value \\
\hline Baseline & & & NS \\
Atrial septal aneurysm (\%) & 20 & 30 & NS \\
Degree of shunt & 2 & 4 & \\
$\quad$ Minimal (\%) & 20 & 18 & NS \\
$\quad$ Moderate (\%) & 78 & 78 & \\
$\quad$ Severe (\%) & $36(5)$ & $36(5)$ & \\
Left atrial diameter (mm) & $68(5)$ & $67(5)$ & 0.004 \\
Left ventricular EF (\%) & & & \\
Follow up & & & \\
Residual shunt at six months & 8 & 2 & \\
$\quad$ Minimal (\%) & 10 & 4 & \\
$\quad$ Moderate (\%) & 16 & & \\
$\quad$ Severe (\%) & & & \\
\hline Values are mean (SD) or per cent. & & \\
EF, ejection fraction; PFO, patent foramen ovale. & &
\end{tabular}




\begin{tabular}{|llll}
\hline Table 3 Implantation procedure & & & \\
\hline & $\begin{array}{l}\text { PFO STAR } \\
(\mathbf{n}=50)\end{array}$ & $\begin{array}{l}\text { Amplatzer PFO } \\
\text { occluder (n=5) }\end{array}$ & p Value \\
\hline Procedural success (\%) & 100 & 100 & 0.09 \\
1 placement attempt & 5 & 1 & $\mathrm{NS}$ \\
Procedure time (min) (mean (SD)) & $24(9)$ & $20(9)$ & 0.004 \\
Fluoroscopy time (min) (mean (SD)) & $9(6)$ & $4(2)$ & $<0.001$ \\
Sheath size (French) (mean (SD)) & $12.0(0.9)$ & $9.0(0.9)$ & \\
Size of device & $18 \mathrm{~mm}: 1$ & $25 \mathrm{~mm}: 32$ & \\
& $22 \mathrm{~mm}: 11$ & $35 \mathrm{~mm}: 18$ & \\
& $26 \mathrm{~mm}: 24$ & & \\
& $30 \mathrm{~mm}: 10$ & & \\
Procedural complications & $35 \mathrm{~mm}: 4$ & & \\
Device embolisation & 2 & 0 & \\
Cardiac tamponade & 1 & 0 & \\
AV fistula & 1 & 0 & \\
Embolisation of air, with transient symptoms & 4 & 1 & \\
\hline Values are $\mathrm{n}$ unless stated. & & & \\
\hline
\end{tabular}

randomised clinical trials, a case-control study showed that percutaneous PFO closure was at least as effective as medical treatment in reducing the incidence of recurrent cerebrovascular ischaemic events, and more effective in patients with more than one previous cerebrovascular ischaemic event. ${ }^{23}$ These promising results have been derived from studies employing transseptal occlusion devices primarily designed for percutaneous treatment of atrial septal defects rather than PFOs. In our experience, important shortcomings of some of these devices included a relatively high incidence of procedural complications (up to $10 \%$ ) and incomplete PFO occlusion (up to $50 \%$ with the Sideris buttoned device). ${ }^{16}$ The recent advent of two dedicated PFO devices, the STAR and the Amplatzer, is aimed at facilitating implantation and improving procedural outcome and complete septal closure. Nevertheless, they differ in design and technical properties.

Within the limits of a non-randomised study design, our findings provide information on the procedural, echocardiographic, and clinical outcome following percutaneous PFO closure using the STAR and Amplatzer devices. Although device implantation was successful in all cases, more than one placement attempt was more often required with the STAR device than with the Amplatzer device. This entailed not only longer fluoroscopy and procedure times, but was also an independent predictor of the occurrence of procedural complications.

The greater incidence of procedural complications related to the number of device placement attempts is plausible for two reasons. First, transseptal positioning of the intravascular sheath requires meticulous evacuation of air to prevent embolism, with each additional transseptal sheath manipulation imposing an increased risk of such complications. Second, in contrast to the Amplatzer device, which can be retrieved into the sheath in the heart in case of false positioning and immediately redeployed, the STAR device requires complete removal from the body to realign the left sided wire frame into its correct orientation before repeat device placement, thus introducing an additional risk of air embolism. The difference in sheath size between the two devices appears irrelevant in the light of the venous access route. However, it cannot be excluded that the observed complications of an arteriovenous fistula and cardiac tamponade in the case of the STAR device were related to the sheath size. From the more frequent attempts to achieve satisfactory device position as well as the observation of two device embolisations in the case of the STAR device, we infer that transseptal positioning and fixation are more stable with the Amplatzer device, possibly because of its bulkier body (figs 1 and 2). A prerequisite for percutaneous PFO closure must be a very low incidence of procedural complications, which favours the Amplatzer device.

Complete PFO closure is another important prerequisite, as a residual shunt following percutaneous closure has previously been identified as a risk factor for recurrent thromboembolic events. ${ }^{16}$ The higher incidence and more severe degree of residual shunting with the STAR than with the Amplatzer device suggests that disc apposition was inferior with the STAR device, particularly when using the longer disc connector. The Amplatzer device achieved complete PFO closure in 47 of 50 patients with only a minimal or moderate residual shunt deemed insignificant in three patients, which corresponds to the rate observed by other investigators. ${ }^{24}$ Thus the Amplatzer attains closure results comparable to surgical PFO closure. ${ }^{21} 22$ Interestingly, device disc sizes of $30 \mathrm{~mm}$ and greater showed a strong trend towards a higher incidence of residual shunt. Thus larger

Table 4 Predictors of procedural complications and residual shunt

\begin{tabular}{|c|c|c|c|}
\hline & RR & $95 \% \mathrm{Cl}$ & p Value \\
\hline \multicolumn{4}{|l|}{ Predictors of procedural complications } \\
\hline PFO STAR device & 8.8 & 1.1 to 74.4 & 0.04 \\
\hline$>1$ placement attempt & 8.5 & 1.3 to 55.8 & 0.03 \\
\hline \multicolumn{4}{|l|}{ Predictors of significant residual shunt } \\
\hline PFO STAR device & 8.4 & 1.8 to 40.1 & 0.01 \\
\hline $5 \mathrm{~mm}$ disc connector with STAR device & 6.1 & 1.1 to 34.0 & 0.04 \\
\hline Postprocedural shunt at day 1 & 1.9 & 1.1 to 3.5 & 0.04 \\
\hline Device size $\geqslant 30 \mathrm{~mm}$ & 2.9 & 0.9 to 9.7 & NS \\
\hline Atrial septal aneurysm & 2.3 & 0.7 to 7.3 & NS \\
\hline Severe shunt at baseline & 2.0 & 0.5 to 8.7 & NS \\
\hline
\end{tabular}




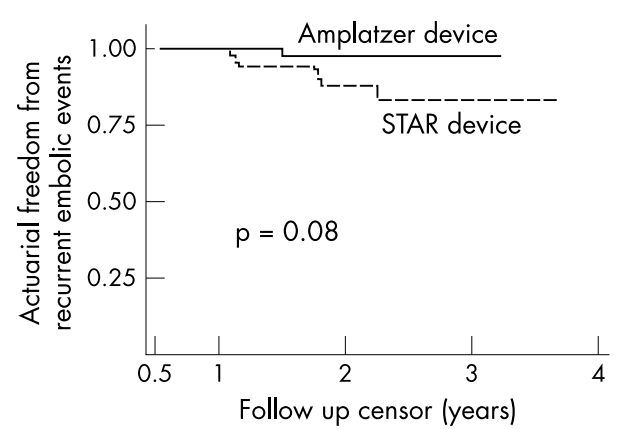

Figure 3 Actuarial freedom from the combined end point of recurrent transient ischaemic attack or stroke in relation to device type.

device discs attach less snugly to the septum, which hinders endothelialisation.

Clinical outcome tended to be better with the Amplatzer than with the STAR device with respect to recurrent thromboembolic events. This trend cannot be explained by the higher occlusion rate, as only one of the recurrent events took place in the setting of a residual shunt. Thrombogenicity of the left sided device surface may also play a role. Five of seven self reported neurological events were confirmed during physical examination or neuroimaging. We included the two self reported events without documentation in the analysis owing to their similarity with the index event. They occurred after verified complete PFO closure, suggesting an aetiology other than paradoxical embolism. All patients recovered completely within seven days, as opposed to the more severe index event leading to percutaneous PFO closure. Furthermore, there were no late device related complications such as material fatigue, infection, embolisation, perforation, or erosion. Notwithstanding, the follow up period of our study is relatively short.

\section{Study limitations}

Our findings of easier device implantation and more complete PFO closure with the Amplatzer than the STAR device are based on a non-randomised study design and therefore subject to bias. Although both patient groups were well balanced with respect to clinical and echocardiographic baseline characteristics, a selection bias with respect to unmeasured variables cannot be excluded. However, the procedure was undertaken by a single operator thus minimising potential differences in the level of experience. The follow up period was relatively short and so limited our ability to detect potential differences in the clinical outcome.

\section{Conclusions}

In this non-randomised study, percutaneous PFO closure with the Amplatzer device was simpler and associated with fewer procedural complications and more complete PFO occlusion than with the STAR device. Owing to the nonrandomised study design, firm conclusions about the superiority of one device over the other cannot be drawn. However, the findings underline the importance of device design for successful percutaneous PFO closure, which should be addressed in future studies.
Authors' affiliations

M Schwerzmann, S Windecker, A Wahl, H Mehta, C Seiler, B Meier, Cardiology, Swiss Cardiovascular Centre Bern, University Hospital Inselspital, Bern, Switzerland

K Nedeltchev, H Mattle, Neurology, University Hospital Inselspital, Bern

\section{REFERENCES}

1 Lechat $P$, Mas JL, Lascault $G$, et al. Prevalence of patent foramen ovale in patients with stroke. N Engl J Med 1988:318:1148-52.

2 Godart F, Rey C, Prat A, et al. Atrial right-to-left shunting causing severe hypoxaemia despite normal right-sided pressures. Report of 11 consecutive cases corrected by percutaneous closure. Eur Heart J 2000;21:483-9.

3 Bansal RC, Marsa RJ, Holland D, et al. Severe hypoxemia due to shunting through a patent foramen ovale: a correctable complication of right ventricular infarction. J Am Coll Cardiol 1985;5:188-92.

4 Amsel BJ, Rodrigus I, De Paep R, et al. Right-to-left flow through a patent foramen ovale in acute right ventricular infarction. Two case reports and a proposal for management. Chest 1995;108:1468-71.

5 Chevrolet JC, Junod AF. [Interauricular right-left shunt: a serious complication of primary pulmonary arterial hypertension]. Schweiz Med Wochenschr 1985; 115:1348-50.

6 Wilmshurst PT, Byrne JC, Webb-Peploe MM. Relation between interatrial shunts and decompression sickness in divers. Lancet 1989;ii:1302-6.

7 Schwerzmann M, Seiler C, Lipp E, et al. Relation between directly detected patent foramen ovale and ischemic brain lesions in sport divers. Ann Intern Med 2001;134:21-4.

8 Del Sette M, Angeli S, Leandri M, et al. Migraine with aura and right-to-left shunt on transcranial Doppler: a case-control study. Cerebrovasc Dis 1998;8:327-30.

9 Wilmshurst PT, Nightingale S, Walsh KP, et al. Effect on migraine of closure of cardiac right-to-left shunts to prevent recurrence of decompression illness or stroke or for haemodynamic reasons. Lancet 2000;356:1648-51.

10 Overell JR, Bone I, Lees KR. Interatrial septal abnormalities and stroke: a meta-analysis of case-control studies. Neurology 2000;55:1172-9.

11 Schuchlenz HW, Weihs W, Horner S, et al. The association between the diameter of a patent foramen ovale and the risk of embolic cerebrovascular events. Am J Med 2000; 109:456-62.

12 De Castro S, Cartoni D, Fiorelli M, et al. Morphological and functional characteristics of patent foramen ovale and their embolic implications. Stroke 2000;31:2407-13.

13 Mas JL, Arquizan C, Lamy C, et al. Recurrent cerebrovascular events associated with patent foramen ovale, atrial septal aneurysm, or both. N Engl J Med 2001;345:1740-6.

14 Bridges ND, Hellenbrand W, Latson L, et al. Transcatheter closure of patent foramen ovale after presumed paradoxical embolism. Circulation 1992;86:1902-8.

15 Hung J, Landzberg MJ, Jenkins KJ, et al. Closure of patent foramen ovale for paradoxical emboli: intermediate-term risk of recurrent neurological events following transcatheter device placement. J Am Coll Cardiol 2000;35:1311-16

16 Windecker S, Wahl A, Chatterjee T, et al. Percutaneous closure of patent foramen ovale in patients with paradoxical embolism: long-term risk of recurrent thromboembolic events. Circulation 2000;101:893-8.

17 Wahl A, Meier B, Haxel B, et al. Prognosis after percutaneous closure of patent foramen ovale for paradoxical embolism. Neurology 2001;57:1330-2

18 Han YM, Gu X, Titus JL, et al. New self-expanding patent foramen ovale occlusion device. Cathet Cardiovasc Intervent 1999;47:370-6.

19 Peduzzi P, Concato J, Kemper E, et al. A simulation study of the number of events per variable in logistic regression analysis. J Clin Epidemiol 1996;49:1373-9.

20 Bogousslavsky J, Garazi S, Jeanrenaud X, et al. Stroke recurrence in patients with patent foramen ovale: the Lausanne Study. Lausanne Stroke with Paradoxal Embolism Study Group. Neurology 1996:46:1301-5.

21 Dearani JA, Ugurlu BS, Danielson GK, et al. Surgical patent foramen ovale closure for prevention of paradoxical embolism-related cerebrovascular ischemic events. Circulation 1999;100:11171-5.

22 Ruchat $\mathbf{P}$, Bogousslavsky J, Hurni $M$, et al. Systematic surgical closure of patent foramen ovale in selected patients with cerebrovascular events due to paradoxical embolism. Early results of a preliminary study. Eur J Cardiothorac Surg 1997; 11:824-7

23 Windecker S, Wahl A, Schwerzmann M, et al. Comparison of medical treatment with percutaneous closure of patent foramen ovale for secondary prevention of TIAs and strokes: a case-control study [abstract]. J Am Coll Cardiol 2002;39:265A

24 Bruch L, Parsi A, Grad MO, et al. Transcatheter closure of interatrial communications for secondary prevention of paradoxical embolism: singlecenter experience. Circulation 2002;105:2845-8. 